\title{
Analysis of selected factors influencing seroma formation in breast cancer patients undergoing mastectomy
}

Jacek Zieliński', Radosław Jaworski², Ninela Irga ${ }^{3}$, Janusz Wiesław Kruszewskiª , Janusz Jaskiewicz ${ }^{1}$

1Department of Surgical Oncology, Medical University of Gdansk, Poland 2Department of Pediatric Cardiac Surgery, Mikolaj Kopernik Pomeranian Centre of Traumatology, Gdansk, Poland

3Department of Pediatrics, Hematology, Oncology and Endocrinology,

Medical University of Gdansk, Poland

${ }^{4}$ Division of Propedeutics of Oncology, Medical University of Gdansk, Poland

Submitted: 26 January 2011

Accepted: 11 April 2011

Arch Med Sci 2013; 9, 1: 86-92

DOI: 10.5114/aoms.2012.29219

Copyright @ 2013 Termedia \& Banach

\section{Abstract}

Introduction: The aim of the work was to analyze the impact of selected factors on the incidence of seroma formation in breast cancer patients undergoing mastectomy.

Material and methods: One hundred and fifty breast cancer patients were prospectively enrolled in the study. All patients had mastectomy performed using the same operative technique with electrocoagulation. The amount of seroma formed after surgery and its duration were correlated with selected demographic, clinical and pathological parameters.

Results: The cumulative total seroma volume collected by the end of treatment was higher and the overall time of seroma treatment was longer in patients over the age of 60 years ( $p=0.001$ and $p=0.001$ respectively). Duration of seroma was significantly longer in obese patients $(p=0.036)$. The cumulative total seroma volume collected by the end of treatment was higher and the overall time of seroma treatment was longer in patients who had over $130 \mathrm{ml}$ of lymph drained during the first 24 postoperative hours $(p<0.001$ and $p=0.001$ respectively). Additionally, longer duration of seroma was observed in patients with pathological stage I and II according to TNM-UICC $(p=0.042)$ and in patients with $\geq 1200 \mathrm{~g}$ weight resected of mammary gland $(p=0.05)$. Conclusions: Age and obesity are important prognostic factors influencing seroma formation in breast cancer patients undergoing mastectomy. The amount of lymph formed during first postoperative day may have predictive value in assessing cumulative total seroma volume collected during treatment and its overall duration.

Key words: seroma, drain, breast cancer, mastectomy, axillary dissection.

\section{Introduction}

Despite more and more common application of chemotherapy and radiotherapy in management of breast cancer patients, surgery remains the gold standard of treatment. Depending on the stage of disease progression, either modified radical mastectomy (MRM) or breast conserving therapy $(\mathrm{BCT})$ is performed [1]. Axillary dissection is one of the elements

\author{
Corresponding author: \\ Jacek Zieliński MD, PhD \\ Department \\ of Surgical Oncology \\ Medical University \\ of Gdansk \\ 7 Debinki Str. \\ 80-952 Gdansk, Poland \\ Phone: +48 583492440 \\ Fax: +48583492440 \\ E-mail: jaziel@gumed.edu.pl
}


of surgical treatment of breast cancer. In low-stage cases it can be replaced with sentinel lymph node dissection if there are no contraindications for the later procedure. Seroma formation is one of the early complications of axillary dissection. It occurs in $15-85 \%$ of cases [2, 3]. In the group of breast cancer patients undergoing surgical procedures seroma formation is caused by accumulation of lymph in the space under cutaneous flaps or in the area of the axilla $[1,4,5]$. To date, neither detailed pathogenesis nor fully efficient methods of prevention of seroma formation have been established [4-8].

In order to reduce seroma formation (SF) a number of procedures have been proposed. They include drainage of the operative wound [6], external compression dressing [9], diathermy performed during surgery, ultrasound, argon, laser, harmonic scalpel [10], endoscopic procedures [11, 12], various techniques of axillary space closure $[3,13]$, fibrin glue [14-20], sclerotherapy using tetracyclines [21] and tranexamic acid application [7, 9]. However, no standard resulting in effective diminution of SF incidence following axillary dissection has yet been established.

The aim of the current work was to assess the impact of selected demographic, clinical and pathological parameters on seroma formation in breast cancer patients undergoing mastectomy, as the first step towards establishing a comprehensive management protocol for prevention of seroma formation and its treatment.

\section{Material and methods}

Breast cancer patients treated with MRM alone or with MRM performed after a course of neoadjuvant chemotherapy were enrolled in the study. All patients were treated in the Department of Oncological Surgery in Gdansk between July 2009 and March 2010. The present prospective trial was performed according to the guidelines of the Ethics Examining Committee of Human Research at the Medical University of Gdansk, Poland (approval no. 196/2009). All surgical procedures were performed by surgical oncology specialists after obtaining written informed consent regarding participation in the trial. Electrocoagulation (Excalibur, CONMED, USA) using a monopolar electrode was used for tissue cutting. The extent of axillary dissection was identical in all patients and comprised lymph nodes of levels I and II according to TNM-UICC, but preserving thoracodorsal and long thoracic nerves [22]. The wound was managed using silicone active drainage (Galmed, Poland) introduced through the lower flap in the axillary region. The number of drains depended on the extent of intraoperative bleeding and the individual judgment of the operator. After MRM, still in the operative theater, the removed mammary gland was weighed. In the postoperative period all patients had their forearm elevated. Mobilization of the upper extremity was started already on postoperative day one. On postoperative day one or two the patients were discharged home equipped with drainage and a special chart for monitoring the amount of lymph collected. If, for three consecutive days, not more than 20-40 ml/day of lymph was collected, the drainage was removed. In cases where after drainage removal lymph was noted in the postoperative wound, additional punctures were performed. In case of an infection, antibiotic treatment was prescribed.

All patients had cumulative total seroma volume measured, which comprised cumulative total lymph volume collected through drainage and any additional punctures. Additionally, from the first postoperative day, total time of seroma treatment was measured. Overweight and obesity were defined according to body mass index (BMI) values as proposed by the World Health Organization (WHO) ( $\geq 25 \mathrm{~kg} / \mathrm{m}^{2}$ and $\geq 30 \mathrm{~kg} / \mathrm{m}^{2}$, respectively) [22].

\section{Statistical analysis}

Data that had normal distribution were assessed using the test for equality of means after first determining whether they were normally distributed in view of the results of Kolmogorov-Smirnov or Shapiro-Wilk tests. Non-parametric U Mann-Whitneytest was used to assess the data that were not normally distributed. For continuous variables the mean value and its range were evaluated. Categorical variables were described in terms of number and percentage of each subgroup, the respective values rounded up to one decimal place. The relationships between categorical variables were assessed using Pearson $\chi^{2}$ test and, in the case of subgroups comprising less than 5 cases, a Yates correction was applied. Pearson test was used to evaluate linear correlations. Statistical analysis was performed using SPSS v. 13.0 (SPSS Inc, USA) and Statistica v. 8.0 (Stat Soft Inc, USA).

\section{Results}

In the period between July 2009 and March 2010, 150 breast cancer patients were qualified for MRM. Patient mean age was 58.4 years. Clinical and pathological characteristics of the analyzed group are summarized in Table I. The average hospitalization time was 1.8 days (range 1-6 days). In view of the BMI values 77 patients (51.3\%) were classified as overweight and 39 (26.0\%) were diagnosed as obese. Twenty-six patients (17.3\%) received prior neoadjuvant chemotherapy. Distribution of clinical and pathological stages of the disease in the analyzed group of patients is summarized in Table I. None of the patients participating in the trial was diagnosed with stage IV disease. In 4 patients 
(2.7\%), all over 60 years of age, infectious complications occurred. Patients over 60 years of age in comparison with younger women had significantly higher total seroma volume (mean $1658 \mathrm{ml}$ vs. $1258 \mathrm{ml} ; p=0.001)$ and longer total time of seroma treatment (mean 24 days vs. 21 days; $p=0.001$ ) (Table II). Moreover, in the group of older patients higher cumulative total lymph volume collected through drainage was observed (mean $1569 \mathrm{ml}$ vs. $1222 \mathrm{ml} ; p=0.002$ ) and cumulative total lymph volume collected during punctures (mean $113 \mathrm{ml}$ vs. $61 \mathrm{ml} ; p=0.001)$ in relation to patients under the age of 60 years.

In the group of obese patients longer total time of seroma treatment was observed when compared to non-obese subjects (mean 25.1 days vs. 21.3 days; $p=0.036$ ). Additionally, in this subgroup of patients larger volumes of lymph were collected on the consecutive postoperative days (Table II).

Patients who received prior neoadjuvant chemotherapy had lower cumulative total lymph volume collected through drainage (mean $1126 \mathrm{ml}$ vs. $1427 \mathrm{ml} ; p=0.024$ ) and lower seroma volume collected by postoperative day 10 (mean $711 \mathrm{ml}$ vs. $934 \mathrm{ml} p=0.037$ ) than patients who were treated with MRM only.

Table I. Demographic, clinical and pathological characteristics of breast cancer patients undergoing mastectomy in the Department of Surgical Oncology in Gdansk $(n=150)$

\begin{tabular}{|c|c|c|}
\hline \multicolumn{2}{|c|}{ Age [years]* } & $58.4(25-83)$ \\
\hline \multicolumn{2}{|c|}{ Weight $[\mathrm{kg}]^{\star}$} & $72.1(49-127)$ \\
\hline \multicolumn{2}{|c|}{ Height $[\mathrm{cm}]^{*}$} & $1.62(1.5-1.78)$ \\
\hline \multicolumn{2}{|c|}{$\mathrm{BMI}\left[\mathrm{kg} / \mathrm{m}^{2}\right]^{\star}$} & $27.4(19.1-50.9)$ \\
\hline \multirow[t]{3}{*}{ CTNM } & । & 82 (54.7\%) \\
\hline & II & $60(40.0 \%)$ \\
\hline & III & $8(5.3 \%)$ \\
\hline \multirow[t]{3}{*}{ pTNM } & I & 45 (30.0\%) \\
\hline & $\|$ & 72 (48.0\%) \\
\hline & III & $33(22.0 \%)$ \\
\hline \multicolumn{2}{|c|}{ Hospitalization [days]* } & $1.8(1-6)$ \\
\hline \multicolumn{2}{|c|}{ Number of resected lymph nodes* } & $15.9(0-43)$ \\
\hline \multicolumn{3}{|c|}{ Number of resected lymph nodes } \\
\hline & $0-15$ & $73(48.7 \%)$ \\
\hline & $\geq 16$ & $77(51.3 \%)$ \\
\hline \multicolumn{3}{|c|}{ Weight of resected mammary gland [g] } \\
\hline & $<1200$ & 99 (66\%) \\
\hline & $\geq 1200$ & $51(34 \%)$ \\
\hline
\end{tabular}

*Mean (range); BMI - body mass index, MRM - modified radical mastectomy, CTNM - clinical classification of malignant tumors according to TNM-UICC [20], PTNM - pathological classification of malignant tumors according to TNM-UICC [20]
Pathological stage of disease progression assessed according to PTNM-UICC [22] had an impact on total seroma volume and total time of seroma treatment. In patients in stage I and II higher total seroma volume (mean $1468 \mathrm{ml}$ vs. $1315 \mathrm{ml}$; $p=0.042)$ and longer total time of seroma treatment (mean 23.4 days vs. 18.3 days; $p=0.032$ ) were observed in relation to stage III patients.

Drainage exceeding $130 \mathrm{ml}$ during the first 24 postoperative h correlated with higher total seroma volume (mean $1708 \mathrm{ml}$ vs. $1086 \mathrm{ml} ; p<0.001$ ) and longer total time of seroma treatment (mean 24 days vs. 21 days; $p=0.001$ ).

It was found that the weight of the resected mammary gland had an effect on total time of seroma treatment. Patients with $>1200 \mathrm{~g}$ weight of the mammary gland had a longer total time of seroma treatment compared to those with $<1200 \mathrm{~g}$ (mean 23.7 days vs. 21.6 days; $p=0.05$ ) (Table II).

The number of resected lymph nodes had an effect on the volume of seroma formed during the first postoperative days. Patients who had 16 or more lymph nodes removed had significantly higher volumes of seroma collected during the first 5 postoperative days compared with patients who had 15 or less lymph nodes removed (mean $652 \mathrm{ml}$ vs. $558 \mathrm{ml} ; p=0.05$ ) (Table II).

Preliminary analysis revealed that patients who had two drains placed had higher volumes of seroma formed during the first few postoperative days than the patients who had only one drain. Surgeons were more prone to place two drains in obese patients than those with $\mathrm{BMI}<30 \mathrm{~kg} / \mathrm{m}^{2}(15 / 39$ (38.5\%) vs. $12 / 111(10.8 \%) ; p=0.022)$.

Additionally, analyses of linear correlations were performed. A strong correlation between total seroma volume and total time of seroma treatment ( $K=0.743 ; p<0.001)$ was observed, whilst total seroma volume and volume of seroma collected on postoperative day one were only moderately correlated $(K=0.353 ; p<0.001)$ (Figures 1 and 2$)$.

\section{Discussion}

Already at the beginning of the $20^{\text {th }}$ century the first studies evaluating methods of reducing seroma formation after breast amputation surgery were conducted. In 1913 Halsted described a suturing technique of attaching a flap to the pectoral muscle fascia in order to reduce seroma formation [24]. Drainage of the postoperative wound after modified radical mastectomy was first proposed by Murphy in 1947 [25, 26]. In a few published studies it has been suggested that the type of diathermy used during surgery may influence seroma formation in the postoperative period [10]. However, Michielsen et al. observed that application of bipolar diathermy, when compared to monopolar diathermy, significantly prolongs the surgical pro- 
Table II. Factors influencing cumulative total seroma volume (Vt) and total time of seroma treatment (Tt) in breast cancer patients undergoing mastectomy in the Department of Surgical Oncology in Gdansk $(n=150)$

\begin{tabular}{|c|c|c|c|c|c|}
\hline Factor & & & Mean & $95 \% \mathrm{Cl}$ & Value of $p$ \\
\hline \multirow[t]{4}{*}{ Age [years] } & $<60$ & Vt & $1258 \mathrm{ml}$ & $1008-1509 \mathrm{ml}$ & \multirow[t]{2}{*}{0.001} \\
\hline & $\geq 60$ & Vt & $1658 \mathrm{ml}$ & $1417-1899 \mathrm{ml}$ & \\
\hline & $<60$ & $\mathrm{Tt}$ & 21 days & $16-26$ days & \multirow[t]{2}{*}{0.001} \\
\hline & $\geq 60$ & $\mathrm{Tt}$ & 24 days & 21-26 days & \\
\hline \multirow[t]{8}{*}{$\mathrm{BMI}\left[\mathrm{kg} / \mathrm{m}^{2}\right]$} & $<29.9$ & $\mathrm{Tt}$ & 21.3 days & 17.6-25.0 days & \multirow[t]{2}{*}{0.036} \\
\hline & $\geq 30$ & Tt & 25.1 days & 20.7-29.5 days & \\
\hline & $<29.9$ & V3 & $397 \mathrm{ml}$ & $360-434 \mathrm{ml}$ & \multirow[t]{2}{*}{0.01} \\
\hline & $\geq 30$ & V3 & $492 \mathrm{ml}$ & $425-559 \mathrm{ml}$ & \\
\hline & $<29.9$ & V5 & $573 \mathrm{ml}$ & $518-629 \mathrm{ml}$ & \multirow[t]{2}{*}{0.013} \\
\hline & $\geq 30$ & V5 & $727 \mathrm{ml}$ & $625-828 \mathrm{ml}$ & \\
\hline & $<29.9$ & V10 & $836 \mathrm{ml}$ & $735-938 \mathrm{ml}$ & 0.048 \\
\hline & $\geq 30$ & V10 & $1063 \mathrm{ml}$ & $846-1279 \mathrm{ml}$ & \\
\hline \multirow[t]{4}{*}{ Neoadjuvant chemotherapy } & No & $\mathrm{Vd}$ & $1427 \mathrm{ml}$ & $1242-1612 \mathrm{ml}$ & \multirow[t]{2}{*}{0.024} \\
\hline & Yes & $\mathrm{Vd}$ & $1126 \mathrm{ml}$ & $658-1594 \mathrm{ml}$ & \\
\hline & No & V10 & $934 \mathrm{ml}$ & $836-1032 \mathrm{ml}$ & \multirow[t]{2}{*}{0.037} \\
\hline & Yes & V10 & $711 \mathrm{ml}$ & 430-992 ml & \\
\hline \multirow[t]{4}{*}{ pTNM } & Stage I and II & Vt & $1468 \mathrm{ml}$ & $1288-1648 \mathrm{ml}$ & \multirow[t]{2}{*}{0.042} \\
\hline & Stage III & Vt & $1315 \mathrm{ml}$ & $805-1825 \mathrm{ml}$ & \\
\hline & Stage I and II & $\mathrm{Tt}$ & 23.4 days & 19.8-27.0 days & 0.032 \\
\hline & Stage III & $\mathrm{Tt}$ & 18.3 days & 14.3-22.2 days & \\
\hline \multirow{4}{*}{$\begin{array}{l}\text { Seroma formation during } \\
\text { first } 24 \text { postoperative } h \text { [ml] }\end{array}$} & $<130$ & Vt & $1086 \mathrm{ml}$ & 857-1315 ml & \multirow[t]{2}{*}{$<0.001$} \\
\hline & $\geq 130$ & Vt & $1708 \mathrm{ml}$ & $1461-1955 \mathrm{ml}$ & \\
\hline & $<130$ & $\mathrm{Tt}$ & 21 days & 14.6-26.5 days & \multirow[t]{2}{*}{0.001} \\
\hline & $\geq 130$ & Tt & 24 days & 21.2-26.1 days & \\
\hline \multirow{2}{*}{$\begin{array}{l}\text { Weight of resected mammary } \\
\text { gland }[g](n=135)\end{array}$} & $<1200$ & $\mathrm{Tt}$ & 21.6 days & 16.9-26.2 days & \multirow[t]{2}{*}{0.05} \\
\hline & $\geq 1200$ & Tt & 23.7 days & 20.2-27.3 days & \\
\hline \multirow{2}{*}{$\begin{array}{l}\text { Number of resected lymph } \\
\text { nodes }(n=135)\end{array}$} & $0-15$ & V5 & $558 \mathrm{ml}$ & $483-633 \mathrm{ml}$ & \multirow[t]{2}{*}{0.045} \\
\hline & $\geq 16$ & V5 & $652 \mathrm{ml}$ & $590-713 \mathrm{ml}$ & \\
\hline
\end{tabular}

$B M I$ - body mass index, obesity: BMI $\geq 30 \mathrm{~kg} / \mathrm{m}^{2}$, pTNM - pathological classification of malignant tumors according to TNM-UICC [20], $V t$ - cumulative total seroma volume, $T t$ - total time of seroma treatment, Vd-cumulative total seroma volume collected through drainage, V2 - seroma volume collected by postoperative day 2, V3 - seroma volume collected by postoperative day 3, V5 - seroma volume collected by postoperative day 5, V10 - seroma volume collected by postoperative day 10; $\mathrm{Cl}$ - confidence interval

cedure [27]. In the present study all patients were treated using monopolar diathermy; therefore we could not assess the effect of the type of diathermy on duration of the surgery.

Despite a wide number of proposed options of SF management, to date no optimal and fully efficient algorithm has been established [6]. It appears that only comprehensive analysis of putative factors influencing seroma formation may eventually allow the development of methods effective in reducing duration of SF and hospitalization, improving patients' quality of life, decreasing the number of follow-up visits in the postoperative period and, as a result, reducing the overall costs of treatment [28-30]. Some authors suggest that effective seroma treatment may reduce incidence of wound infections and lymphedema of the upper extremity as well as lower the risk of lymphatic cyst formation [6, 31].

In the current study we found that age, BMI, history of prior neoadjuvant chemotherapy, stage of the disease according to PTNM and the volume of seroma collected during the first 24 postoperative $h$ have an influence on seroma formation and may be considered as seroma formation prognostic factors in patients undergoing modified radical mastectomy. The possibility to assess the risk of SF may result in future in better postoperative care of patients subject to modified radical mastectomy. 


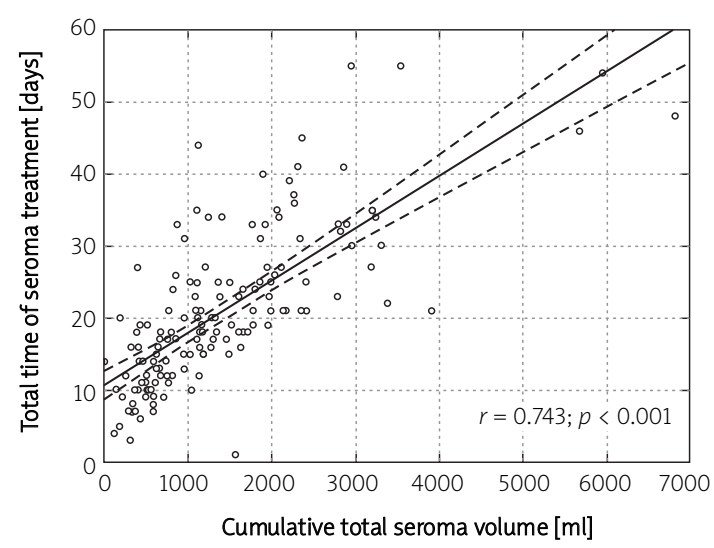

Figure 1. Graphical illustration of the correlation between the total time of seroma treatment and the cumulative total seroma volume in breast cancer patients undergoing mastectomy $(n=150)$

We also found that patients over the age of 60 years have higher total seroma volume and longer total time of seroma treatment of seroma formation when compared to the group of younger patients. Relatively few reports on the effect of patient age on seroma formation in women undergoing MRM have been published so far [32, 33]. In a study of 359 breast cancer patients Gonzalez et al. reported SF only in $15.9 \%$ of cases [32]. The substantial difference in SF incidence when compared to our study results from the dissimilarity in SF definition used by the authors. In other publications no correlation between patient age and SF incidence were noted $[1,34]$. More to the point, in patients over 60 years of age more often infections of the postoperative wound were observed, which is in line with previously published reports [35]. We report a significant correlation between obesity and higher total seroma volume and longer total time of seroma treatment. This issue remains a major controversy. Neither Gonzalez et al. nor Woodworth et al. observed an effect of obesity on seroma formation [32, 35]. Conversely, Theunissen, despite not analyzing BMI values but only patient weight, noted a correlation between patients' weight and total seroma volume and total time of seroma treatment. The underlying mechanisms are not yet fully understood, but we suppose that in obese people the area of surgical incision is larger, which implies that a higher number of lymphatic vessels may be damaged. Obesity is recognized as a major and rapidly worsening public health problem. Accordingly, introduction of prophylactic measures aimed at reducing the number of obese people may not only lead to shortening duration of seroma treatment in patients undergoing mastectomy but also might reduce the number of complications in the postoperative period [33, 34]. Besides, we have

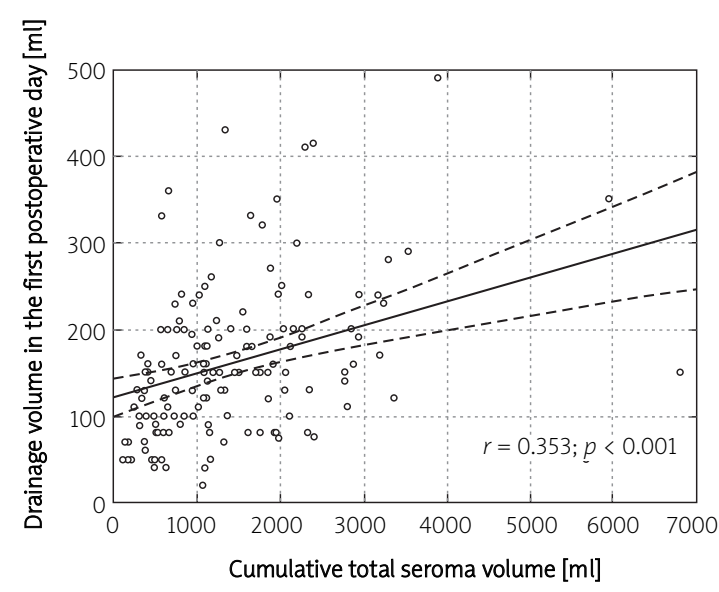

Figure 2. Graphical illustration of the correlation between the volume of drainage collected during the first 24 postoperative $h$ and the cumulative total seroma volume in breast cancer patients undergoing mastectomy $(n=150)$

shown that weight of the resected organ may have prognostic significance for total time of seroma treatment. In our study we found that in patients with weight of the resected organ exceeding $1200 \mathrm{~g}$, significantly longer total time of seroma treatment was observed. Such a correlation was not analyzed in the previous studies with the exception of the Theunissen and Woodworth reports. However, conversely to our findings, the authors did not observe an effect of organ weight on seroma formation [34, 35]. The observed larger cumulative volumes of seroma formed in older patients and in the group of obese patients also have clinical significance, since these two subgroups of patients should undergo more frequent follow-up visits in the postoperative period. Above all, particular attention should be paid in the time just after removal of drainage.

Additionally, we observed that patients who received neoadjuvant chemotherapy prior to MRM had lower lymph volumes collected during the first few postoperative days and lower cumulative total lymph volume collected through drainage. Contrary to our findings, in the previously published reports no effect of neoadjuvant chemotherapy on SF was observed [1, 32, 35]. In view of the aforesaid, further studies assessing the value of neoadjuvant chemotherapy in SF prevention are necessary.

Furthermore, we observed that pathological stage III (assessed according to PTNM-UICC) is associated with lower total seroma volume and shorter total time of seroma treatment when compared to cases having lower stages. We have reviewed the available literature and observed that tumor size and the stage of disease progression were not reported as factors influencing seroma formation after MRM. It appears that lower seroma formation in patients having an advanced pathological stage 
may be attributable to the presence of neoplastic emboli in the lymph vessels obstructing lymph circulation, though our hypothesis has to be validated experimentally.

Also in the current study we found that the volume of lymph collected during the first 24 postoperative $\mathrm{h}$ predicts total seroma volume and total time of seroma treatment. Statistical analysis revealed a significant correlation between these parameters. More to the point, we found that collection of less than $130 \mathrm{ml}$ of lymph on the first postoperative day was related to lower total seroma volume and shorter total time of seroma treatment. Similar observations were previously reported by Theunissen et al., who found a significant correlation between seroma formation on the first day and total seroma volume and total time of seroma treatment.

It appears that routine application of wound drainage is well justified since it contributes to diminishing the space formed during MRM between cutaneous flaps [6]. On the other hand, the number of drains to be placed in patients undergoing mastectomy remains questionable. Our study has shown that application of two drains correlates with higher lymph volumes collected in the first few postoperative days when compared to the patients who received treatment with one drain only. In our opinion, it probably results from the fact that obese patients were more likely to have two drains placed, and this subgroup of patients, as we have already shown, is characterized by increased seroma formation. Previously published studies showed no significant difference in seroma formation between patients having one versus multiple drainage $[6,37,38]$.

The number of lymph nodes removed during surgery was yet another factor analyzed in the current study. We observed that a larger number of lymph nodes resected did not influence total seroma volume and total time of seroma treatment and only correlated with the volume of seroma collected during the first postoperative days. In only one previously published study was such an influence observed [32], while two other studies, by Hashemi and Woodworth, did not report such a correlation [1, 35]. It appears that removal of a larger number of lymph nodes results in greater injury of the lymph vessels. Regrettably, in the available literature little has been published on this subject matter and no clear explanation of the issue has been proposed.

Identification of factors influencing seroma formation is of tremendous importance since it may allow a standard procedure of management of seroma formation in patients undergoing MRM to finally be established. The main aim of treatment optimization is to decrease its duration and to reduce the cumulative volume of seroma formed. It appears that efficient SF management in the early postoperative period is particularly important, since in the first 5 days after surgery wound healing mechanisms are initiated [5]. Besides, better control over SF may contribute to more common implementation of "the short-stay program" that has already been successfully introduced in a number of oncology centers [39]. In essence, shorter SF treatment improves patients' quality of life.

In our opinion the hitherto published studies do not explore sufficiently all the aspects of seroma formation. On the other hand, in-depth analysis of all putative prognostic factors might allow the establishment of better management procedures of patients undergoing MRM.

In conclusion, in view of the results of our study, it seems that age and obesity are significant prognostic factors predicting duration of seroma formation treatment and its cumulative volume in breast cancer patients undergoing mastectomy. In the group of older patients and in the group of obese women, more frequent clinical follow-up is recommended in the postoperative period because of lengthy seroma healing and higher risk of surgical complications. Moreover, we have observed that the volume of lymph collected during the first 24 postoperative $h$ may become a prognostic factor with respect to SF duration and its cumulative volume. Also, the weight of the removed mammary gland had an effect on total time of seroma treatment, while the number of lymph nodes resected during surgery did not affect seroma formation.

The effect of neoadjuvant chemotherapy on seroma formation requires further detailed studies. It appears that identification of as many factors influencing seroma formation as possible may in future allow us to establish a standard of seroma formation management that takes into consideration individual requirements of a particular patient.

\section{Acknowledgments}

We thank all the members of staff of the Department of Surgical Oncology, Medical University of Gdansk and the clinical trial team for their collaboration. We appreciate all patients who participated in the study. Beata Lipska MD, PhD performed language revision of the manuscript.

\section{References}

1. Hashemi E, Kaviani A, Najafi M, Ebrahimi M, Hooshmand H, Montazeri A. Seroma formation after surgery for breast cancer. World I Surg Oncol 2004; 2: 44.

2. Bonnema J, Van Geel AN, Ligtenstein DA, Schmitz PIM, Wiggers T. A prospective randomized trial of high versus low vacuum drainage after axillary dissection for breast cancer. Am J Surg 1997; 173: 76-9.

3. Classe J, Dupre PF, François T, Robard S, Theard JL, Dravet F. Axillary padding as an alternative to closed suction drain for ambulatory axillary lymphadenectomy. A prospective cohort of 207 patients with early breast cancer. Arch Surg 2002; 137: 169-73. 
4. Kuroi K, Shimozuma K, Taguchi T, et al. Pathophysiology of seroma in breast cancer. Breast Cancer 2005; 12: 288-93.

5. Stehbens WE. Postmastectomy serous drainage and seroma: probable pathogenesis and prevention. ANZ J Surg 2003; 73: 877-80.

6. Agrawal A, Ayantunde AA, Cheung KL. Concepts of seroma formation and prevention in breast cancer surgery. ANZ J Surg 2006; 76: 1088-95.

7. Pogson CJ, Adwani A, Ebbs SR. Seroma following breast cancer surgery. Eur J Surg Oncol 2003; 29: 711-7.

8. McCaul JA, Aslaam A, Spooner RJ, Louden I, Cavanagh T, Purushotham AD. Aetiology of seroma formation in patients undergoing surgery for breast cancer. Breast 2000; 9: 144-8.

9. O'Hea BJ, Ho MN, Petrek JA. External compression dressing versus standard dressing after axillary lymphadenectomy. Am J Surg 1999; 177: 450-3.

10. Deo SVS, Shukla NK. Modified radical mastectomy using harmonic scalpel. J Surg Oncol 2000; 74: 204-7.

11. Kuehn T, Santjohanser C, Grab D, Klauss W, Koretz K, Kreienberg R. Endoscopic axillary surgery in breast cancer. $\mathrm{Br}$ J Surg 2001; 88: 698-703.

12. Tagaya N, Kubota K. Experience with endoscopic axillary lymphadenectomy using needlescopic instruments in patients with breast cancer: a preliminary report. Surg Endosc 2002; 16: 307-9.

13. Yiping Gong MB, Juan Xu MB, Jun Shao MS, et al. Prevention of seroma formation after mastectomy and axillary dissection by lymph vessel and dead space closure: a randomized trial. Am J Surg 2010; 200: 352-6.

14. Coppolla C, Fricano S, Vieni S, et al. Does the use fibrin glue prevent seroma formation after axillary lymphadenectomy for breast cancer? A prospective randomized trial in 159 patients. J Surg Oncol 2010; 101: 600-3.

15. Ruggiero R, Procaccini E, Piazza P, et al. Effectiveness of fibrin glue in conjunction with collagen patches to reduce seroma formation after axillary lymphadenectomy for breast cancer. Am J Surg 2008; 196: 170-4.

16. Jain PK, Sowdi R, Anderson ADG, MacFie J. Randomized clinical trial investigating the use of drains and fibrin sealant following surgery for breast cancer. Br J Surg 2004; 91: 54-60.

17. Gilly FN, François Y, Sayag-Beaujard AC, Glehen O, Brachet A, Vignal J. Prevention of lymphorrhea by means of fibrin glue after axillary lymphadenectomy in breast cancer: prospective randomized trial. Eur Surg Res 1998; 30: 439-43.

18. Dinsmore RC, Harris JA, Gustafson RJ. Effect of fibrin glue lymphatic drainage after modified radical mastectomy: a prospective randomized trial. Am Surg 2000; 66: 982-5.

19. Berger A, Tempfer C, Hartmann B, et al. Sealing of postoperative axillary leakage after axillary lymphadenectomy using a fibrin glue coated collagen patch: a prospective randomized study. Breast Cancer Res Treat 2001; 67: 9-14.

20. Ulusoy AN, Polat C, Alvur M, Kandemir B, Bulut F. Effect of fibrin glue on lymphatic drainage and on drain removal time after modified radical mastectomy: a prospective randomized study. Breast J 2003; 9: 393-6.

21. Hackert T, Werner J, Loos M, Buchler MW, Weitz J. Successful doxycyline treatment of lymphatic fistula: report of five cases and review of the literature. Langenbecks Arch Surg 2006; 391: 435-8.

22. Sobin L H, Wittekind C. TNM Classification of malignant tumours. 6th ed. John Wiley\&Sons, New Jersey 2002.

23. World Health Organization. Obesity: Preventing and managing the global epidemic. Report of a WHO Consultation on Obesity, Geneva, 3-5 June 1997 WHO/NUT/NCD/98. 1, Geneva, 1998.
24. Halstead WS. Developments in the skin grafting operations for cancer of the breast. JAMA 1913; 60: 416-8.

25. Murphey BR. The use of atmospheric pressure in obliterating axillary dead space following radical mastectomy. South Surg 1947; 13: 372-5.

26. Gupta R, Pate K, Varshney S, Goddard J, Royle GT. A comparison of 5-day and 8-day drainage following mastectomy and axillary clearance. Eur J Surg Oncol 2001; 27: 26-30.

27. Michielsen DPJ, Coomans D, Engels B, Braeckman JG. Clinical research Bipolar versus monopolar technique for palliative transurethral prostate resection. Arch Med Sci 2010; 6: 780-6.

28. Boman L, Bjorvell H, Cedermark B, Theve NO, Wilking N. Effects of early discharge from hospital after surgery for primary breast cancer. Eur J Surg 1993; 159: 67-73.

29. Holcombe $C$. The satisfaction and savings of early discharge with drain in situ following axillary lymphadenectomy in the treatment of breast cancer. Eur J Surg Oncol 1995; 21: 604-6.

30. Horgan K, Benson EA, Miller A, Robertson A. Early discharge with drain in situ following axillary lymphadenectomy for breast cancer. Breast 2000; 9: 90-2.

31. Stanczyk M, Grala B, Zwierowicz T, Maruszynski M. Surgical resection for persistent seroma, following modified radical mastectomy. World J Surg Oncol 2007; 5: 104.

32. Gonzalez EA, Saltzstein EC, Riedner CS, Nelson BK. Seroma formation following breast cancer surgery. Breast J 2003; 9: 385-8.

33. Petrek JA, Peters MM, Nori S, Knauer C, Kinne DW, Rogatko A. Axillary lymphadenectomy: a prospective, randomized tria of 13 factors influencing drainage, including early or delayed arm mobilization. Arch Surg 1990; 125: 378-82.

34. Theunissen D, Cant PJ, Dent DM. Factors that influence volume and duration of wound drainage after mastectomy and level III axillary node clearance. Breast 2001; 10: 538-9.

35. Woodworth PA, McBoyle MF, Helmer SD, Beamer RL Seroma formation after breast cancer surgery: incidence and predicting factors. Am Surg 2000; 66: 444-57.

36. Nieto A, Lozano M, Moro MT, Keller J, Carralafuente C. Determinants of wound infections after surgery for breast cancer. Zentralbl Gynakol 2002; 124: 429-33.

37. Petrek JA, Peters MM, Cirrincione C, Thaler HT. A prospec tive randomized trial of single versus multiple drains in the axilla after lymphadenectomy. Surg Gynecol Obstet 1992; 175: 405-9.

38. Terrel GS, Singer JA. Axillary vs. combined axillary and pectoral drainage after modified radical mastectomy. Surg Gynecol Obstet 1992; 175: 437-40.

39. De Kok M, Weijden T, Voogd A, et al. Implementation of short-stey programme after breast cancer surgery. Br I Surg 2010; 97: 189-94. 